\title{
Self-forgiveness in romantic relationships: 2. Impact on interpersonal forgiveness
}

\author{
Sara Pelucchi $^{\mathrm{a} *}$, F. Giorgia Paleari ${ }^{\mathrm{b}}$, Camillo Regalia $^{\mathrm{a}}$ and Frank D. Fincham ${ }^{\mathrm{c}}$ \\ ${ }^{a}$ Department of Psychology, Catholic University of Milan, Milan, Italy; ${ }^{b}$ Department of Human and Social Science, University of \\ Bergamo, Bergamo, Italy; ${ }^{c}$ Family Institute, Florida State University, Tallahassee, FL, USA
}

(Received 15 October 2014; accepted 22 January 2015)

\begin{abstract}
Both self-forgiveness and other-forgiveness are associated with greater relationship satisfaction in romantic relationships. The present research examines whether self-forgiveness for a transgression against the partner leads to greater forgiveness of a subsequent partner transgression, and whether this, in turn, predicts greater relationship satisfaction. Study 1 showed that self-forgiveness positively affected other-forgiveness in a scenario-based design employing university students. Study 2 investigated real transgressions between cohabiting partners and showed that self-forgiveness was positively related to relationship satisfaction both directly and indirectly, through other-forgiveness. The results are discussed in terms of their implications for future research.
\end{abstract}

Keywords: self-forgiveness; interpersonal forgiveness; relationship satisfaction; romantic couples

\section{Introduction}

There is a robust association between the quality of a romantic relationship and each partners' physical and psychological well-being (e.g. Baker, McNulty, Overall, Lambert, \& Fincham, 2013; Davila, Karney, Hall, \& Bradbury, 2003; Whisman \& Bruce, 1999). However, transgressions occur in all relationships and can have disruptive effects on both the victim and the perpetrator. The victim may ruminate on his/her suffering wondering how it could have happened and whether the partner can be trusted again. At the same time, the perpetrator may ruminate on what happened and get stuck on questions like 'What kind of person does what I did to my partner?' or 'Can my partner trust me again?'. Both partners may have difficulty in valuing each other and their relationship as much as they did before and experience a decrease in relationship satisfaction.

Self-forgiveness and other-forgiveness (interpersonal forgiveness) are key processes in healing relationships when a transgression occurs (Wieselquist, Rusbult, Foster, \& Agnew, 1999). Specifically, self-forgiveness allows the transgressor to reduce his or her own distress and instead focus on finding an appropriate way to repair the relationship (Holmgren, 1998; Woodyatt \& Wenzel, 2013). On the other hand, interpersonal forgiveness can help the victim to trust his or her partner and to feel safe and valued in the relationship again. Both processes have been found to predict relationship satisfaction and have therefore been viewed as pro-relational coping strategies to deal with transgressions in relationships (Fincham, Hall, \& Beach, 2006; Pelucchi, Paleari, Regalia, \& Fincham, 2013; Strelan \& Covic, 2006).
Research exploring relational outcomes associated with self-forgiveness is however in its infancy. Not surprisingly, psychological mechanisms that might be at work in the self-forgiveness - relationship satisfaction association are unknown. Also, the extent to which selfforgiveness and other-forgiveness are related within the same person remains to be determined. The present research addresses these shortcomings by examining whether forgiving the partner for an offence is facilitated by having forgiven the self for an offence previously committed against the partner. We also examine whether other-forgiveness mediates the link between self-forgiveness and relationship satisfaction.

\section{Self-forgiveness and other-forgiveness}

Self-forgiveness and other-forgiveness share a number of similarities: both are responses to an objective wrong, involve a shift from negative affect, cognitions or motivations to more positive ones, and both take place over time (Tangney, Boone, \& Dearing, 2005). Self-forgiveness is often defined as a process of positive reconnection to the self that follows damage to the self-image caused by committing a transgression (Dillon, 2001). It involves a motivational change whereby the offender over time restores a positive self-image, reduces self-recriminating behaviors, and restores positive emotion toward the self-like benevolence and compassion (Enright \& Developmental Study Group, 1998; Hall \& Fincham, 2005).

Accepting responsibility for the wrongdoing is a prerequisite for genuine self-forgiveness (Fisher \& Exline, 2006; Hall \& Fincham, 2005; Wenzel, Woodyatt, \&

\footnotetext{
*Corresponding author. Email: sara.pelucchi@unicatt.it 
Hedrick, 2012) and promotes other-oriented responses, like offering apologies and amends, which allows one to distinguish self-forgiveness from processes of moral disengagement like self-excusing or self-justification (Fisher \& Exline, 2006). Although self-forgiving individuals experience negative feelings like guilt and shame they do not remain fixated on these feelings (Woodyatt \& Wenzel, 2013). In fact, as transgressors move toward self-forgiveness, they become less condemning of themselves and more prone to let go (but not necessarily rid themselves) of their guilty feelings, possibly as an effect of having enacted reparative behaviors toward the victim (Exline \& Fisher, 2006; Holmgren, 1998). Accordingly, self-forgiveness has been shown to be facilitated by a decrease in the offender's guilt and perceived offence severity, an increase in reparative behaviors toward the victim, and perceived forgiveness by the victim (Hall \& Fincham, 2008).

Similar to self-forgiveness, other-forgiveness has been conceptualized as a motivational change whereby the victim becomes less negatively motivated (vengeful, avoidant) and more benevolent toward the offender (McCullough, Worthington, \& Rachal, 1997). The motivational changes inherent to interpersonal forgiveness are often accompanied by a less negative perception of the offender and more positive feelings toward him or her (Schmith, Gollwitzer, Förster,\& Montada, 2004). There is strong evidence that interpersonal forgiveness is fostered by decreased rumination, less dispositional attribution for the offence, and lower perceived offence severity (McCullough et al., 1998; Paleari, Regalia, \& Fincham, 2005).

Existing research indicates that both self-forgiveness and other forgiveness entail at least two underling dimensions: one negative, assessing avoidant and resentful beliefs, sentiment, and intentions, which denote the lack of forgiveness (or unforgiveness), and one positive, measuring benevolent beliefs, sentiment, and intentions, which indicates the presence of forgiveness. Whereas resentful and benevolent reactions are focused on the offender in both self-forgiveness and interpersonal forgiveness, avoidant reactions are directed toward the offender in interpersonal forgiveness; in self-forgiveness, they are targeted at the victim. Also, unlike interpersonal forgiveness which does not imply reconciliation with the offender, self-forgiveness entails reconciliation with the self (Hall \& Fincham, 2005).

Other-forgiveness and self-forgiveness have been shown to be associated across subjects: Forgiving the self is more likely for the offender as long as the victim has previously forgiven him or her (Hall \& Fincham, 2008). However, no study has investigated whether the two processes are related within the same subject.

If we move from considering self- and other-forgiveness as processes developed in response to a specific offence to seeing them as dispositional traits, we can note that within subject correlations between the disposition to forgive the self and the other are low (Macaskill, Maltby, \& Day, 2002; Mauger et al., 1992; Tangney, Boone, Dearing, \& Reinsmith, 2002; Thompson et al., 2005). As Hodgson and Wertheim (2007) note, however, the magnitude of these within subject correlations may be due to a methodological problem, namely the difficulty in differentiating true self-forgiveness, which requires a sincere admission of responsibility, from pseudo selfforgiveness (Hall \& Fincham, 2005). However, in response to specific offences self-forgiveness and otherforgiveness are moderately associated (e.g. Allemand, Amberg, Zimprich, \& Fincham, 2007; Eaton, Struthers, \& Santelli, 2006; Whol, DeShea, \& Wahkinney, 2008). Thus, the evidence that self-forgiveness and other-forgiveness are weakly correlated within subjects at the trait level does not rule out the possibility that they are more strongly associated in relation to particular offences for which offenders feel responsible. Accordingly, we argue that, besides sharing a number of similarities and being correlated across subjects, as is the case when an offender's self-forgiveness is facilitated by the victim's forgiveness (Hall \& Fincham, 2008), self-forgiveness and otherforgiveness for specific offences may be associated within subjects as well.

The literature on forgiveness and human fallibility provides some arguments and evidence in support of this view. Specifically, Snow (1993) pointed out that offenders who are able to forgive themselves tend to identify more strongly with the transgressor when they are victims. Self-forgivers experience more benevolence and compassion toward the self. Being self-compassionate implies the ability to achieve a stronger awareness of common human fallibility and to recognize similarities between oneself and others (Neff, 2003), an ability that has been shown to foster interpersonal forgiveness (Exline, Baumeister, Zell, Kraft, \& Witviliet, 2008; Wohl, Kuiken, \& Noels, 2006).

The interdependence of couple relationships maximizes similarity and identification between partners: By including the other in the self, people involved in close relationships tend to have similar representations of self and other (Aron, Aron, Tudor, \& Nelson, 1991). Thus, in close relationships it is likely that, as long as a person regains a positive self-image by forgiving himself or herself after a transgression against the partner, the same person is also likely to forgive the partner who has transgressed against him or her.

\section{Forgiveness and relationship satisfaction}

Both self-forgiveness and other-forgiveness are pro-relationship strategies associated with relationship satisfaction. In the case of interpersonal forgiveness, a number 
of longitudinal studies show that it leads partners to evaluate their relationship as more satisfying, committed, and close (Fincham \& Beach, 2007; Paleari et al., 2005, 2009; Tsang, McCullough, \& Fincham, 2006). This happens because by reestablishing mutual trust, interpersonal forgiveness motivates partners to cooperate and accommodate, and to inhibit conflictual behaviors in favor of conciliatory ones (Gordon, Hughes, Tomcik, Dixon, \& Litzinger, 2009; Karremans, VanLange, Ouwerkerk, \& Kluwer, 2003).

As regards self-forgiveness, Pelucchi and colleagues (2013) showed that self-forgiveness is positively related to a greater relationship satisfaction for both the offending and victimized partner (Pelucchi et al., 2013). As these authors argued, people who have difficulties in forgiving themselves are more prone to negative thoughts and feelings, including remorse, rumination, guilt, distrust, and depression, which negatively affect relationship satisfaction (Bookwala, 2012; Carr, Freedman, Cornman, \& Schwarz, 2014; MacKenzie et al., 2014; Maltby, Macaskill, \& Day, 2001; Mauger et al., 1992).

As noted, both self- and other-forgiveness reflect two underlying dimensions. For each type of forgiveness, the negative dimension tends to be more strongly related to relationship variables than the benevolent dimension, especially in short- and medium-term couple relationships (Paleari et al., 2009; Pelucchi et al., 2013). This finding is consistent with a substantial body of literature showing that bad emotions and behavioral patterns have a stronger impact than positive ones (Baumeister, Bratslavsky, Finkenauer, \& Vohs, 2001).

\section{Aims and hypotheses}

The first aim of the present research was to explore whether genuine self-forgiveness for a specific transgression against a romantic partner affects forgiveness of an offence perpetrated by the partner against the self. Based on the literature reviewed earlier, we hypothesized that the more individuals forgive themselves for an offence committed against the partner the more the same individual forgives the partner when subsequently victimized by him or her. This likely happens because, as we argued, selfforgiving offenders are more likely, when victims, to accept both their own and their partner's human fallibility (Neff, 2003; Snow, 1993; Wohl et al., 2006).

The second aim was to determine whether self-forgiveness predicts relationship satisfaction not only directly, but also indirectly through other-forgiveness. As noted, there is evidence that both self-forgiveness and other-forgiveness positively affect relationship satisfaction (Paleari, Regalia, \& Fincham, 2010; Pelucchi et al., 2013). If, as we just argued, self-forgiveness affects other-forgiveness, then it is likely that self-forgiveness is associated with relationship satisfaction partly via other-forgiveness.
Specifically, we hypothesized that the more persons forgive themselves for a transgression against the partner, the more they are likely to forgive a subsequent partner transgression, which will, in turn, lead them to be more satisfied with the relationship.

To address these aims, we conducted two studies using different methodologies. In the first study, self-forgiveness was experimentally manipulated in order to test its effect upon other-forgiveness. In the second study, we examined other-forgiveness as a potential mechanism that might help account for the association between self-forgiveness and relationship satisfaction.

\section{Study 1}

In this study, we used a scenario-based methodology to determine whether forgiving the self for a transgression against the partner predicts more forgiveness of the partner for a subsequent transgression. Besides manipulating selfforgiveness, the type of offence was also manipulated to examine whether self-forgiveness influences other-forgiveness across different offence types. We did not assess self- and other-forgiveness in relation to the same offence type in order to avoid activating a reciprocity or equity norm (I do to others what I do to myself). Because otherforgiveness is likely to vary in relation to the perceived severity of the offence, offence severity was used as a covariate in the analysis.

\section{Method}

Participants and procedure

Eighty-nine undergraduate students (32 men, 57 women; $M$ age $=21$ years old; $S D=2.4$ ) involved in a romantic relationship participated as volunteers in the study. They were randomly assigned to one of the four scenario conditions: forgiveness $v s$. unforgiveness of self for lying $(N=23$ and 19) or forgiveness $v s$. unforgiveness of self for disrespecting $(N=23$ and 24).

In all four conditions, participants had to imagine chatting with their partner and close friends during a dinner party. At some point, the conversation turns on negative events in relationships: A friend asks the subject about a wrongdoing he/she did against the partner and for which he/she felt very responsible. In the lie condition scenarios, the wrongdoing consists of having lied to the partner about something important to him/her. In the disrespecting condition scenarios, the wrongdoing consists of disrespecting the partner by teasing him/her in front of friends. After having remembered the transgression (lying/ disrespecting), the subject imagines having/not having forgiven himself or herself for it. Subsequently, the subject was asked to imagine an offence by the partner who, at the end of the party, disrespects him/her by teasing the subject 
in front of all the friends (for participants assigned to the lying condition) or to have lied to the subject about something important (for participants assigned to the disrespecting condition).

\section{Measures}

Other-forgiveness. After reading the scenario, participants were invited to complete a slightly modified version of the Marital Offence-specific Forgiveness Scale (MOFS; Paleari et al., 2009). The 10-item scale was adapted in order to assess forgiveness for hypothetical offences by unmarried romantic partners (e.g. 'I forgave my wife/husband completely, thoroughly' was altered to 'I would forgive my partner completely, thoroughly'). The scale contains two subscales. The Benevolence subscale (four items), here renamed Forgiveness of Other, investigates the presence of benevolence towards the offending partner, while the Resentment-Avoidance subscale (six items), here renamed Unforgiveness of Other, investigates the presence of resentful and avoidant motivations towards the offending partner. Items were scored on 7-point scales, ranging from $1=$ completely disagree to $7=$ completely agree. Coefficient alpha was .75 and .66 for Forgiveness of Other and Unforgiveness of Other, respectively.

Perceived offence severity. The perceived severity of the offence was assessed by the question: 'How serious would it be if your partner disrespected you by teasing you in front of all friends/lied to you about something important to you?' The item was rated on a 7-point Likert-type scale $(1=$ not serious at all $; 7=$ very serious $)$.

\section{Results}

Descriptive statistics and correlations among the variables investigated are shown in Table 1. To assess the impact of self-forgiveness on the two dimensions of other-forgiveness, we performed a multivariate analysis of covariance (MANCOVA) in which the perceived severity of the offence served as a covariate. As hypothesized, the main effect of self-forgiveness on other-forgiveness dimensions was statistically significant $(F(2,83)=18.37, p=.000$,

Table 1. Correlations among and descriptive statistics for Study 1 variables.

\begin{tabular}{lccc}
\hline & 1 & 2 & 3 \\
\hline 1. Unforgiveness of Other & - & $-.45^{* *}$ & .10 \\
2. Forgiveness of Other & & - & -.13 \\
3. Perceived offence severity & & & - \\
$M$ & 4.05 & 3.95 & 6.10 \\
$S D$ & 1.23 & 1.16 & 1.02 \\
\hline
\end{tabular}

Note: ${ }^{* *} p<.01$. $\left.\eta^{2}=.31\right)$. Follow-up ANCOVAs indicated significant differences between high and low self-forgivers on both dimensions of other-forgiveness (all $p<.001$ ). Namely, self-forgiving subjects had higher levels of Forgiveness of Other and lower levels of Unforgiveness of Other than self-unforgiving subjects (Forgiveness of Other: $M=4.36$; $S D=1.01 ;$ and $M=3.52 ; S D=1.16$, respectively; Unforgiveness of Other: $M=3.45 ; S D=1.06$; and $M=4.71 ; S D=1.07)$.

A significant main effect of offence type on otherforgiveness dimensions was also found $(F(2,83)=4.06$, $p=.02, \eta^{2}=.09$ ). Follow-up ANCOVAs indicated that offence type made a difference in relation to Unforgiveness of Other $(p<.01)$, but not to Forgiveness of Other $(p>.05)$. Subjects were less unforgiving toward the partner when he or she disrespected them than when he or she lied to them $(M=3.74 ; S D=1.34$; and $M=4.34 ; S D=1.08$ respectively). Compared to disrespect toward the self, lying is probably perceived by partners as a wrongdoing that, undermining the mutual trust, has more direct negative effects upon the relationship and for this reason arouses more resentment and avoidance. No significant interaction between self-forgiveness and offence typology was found $(p>.05)$.

The covariate, perceived severity of the offence did not significantly contribute to the model $(p>.05)$; after removing offence severity from the model, the main effect for self-forgiveness was still significant $(F(2,84)=17.03$, $\left.p=.000, \eta^{2}=.29\right)$, whereas the main effect for offence type became marginally significant $(F(2,84)=2.96$, $\left.p=.057, \eta^{2}=.09\right)$. These findings suggest that the effects of self-forgiveness upon other-forgiveness were largely independent of perceived offence severity.

\section{Study 2}

In light of the support obtained in Study 1 for the predicted link between self-forgiveness and other-forgiveness, Study 2 examined whether self-forgiveness for an offence perpetrated against the partner was related to relationship satisfaction both directly and indirectly through other-forgiveness for an offence committed by the partner. Because both self-forgiveness and other-forgiveness are likely to be related to offence severity (Fincham, Jackson, \& Beach, 2005; Hall \& Fincham, 2008), Study 2 tested the hypothesized mediational model while controlling for the perceived severity of both the offence committed and the offence suffered as shown in Figure 1.

In addition to testing a mediational model, Study 2 extends Study 1 in two further respects. First, it overcomes some limitations that are inherent to the scenario-based methodology used in Study 1 (e.g. effects caused by imagined levels of self-forgiveness are likely to be substantially different from actually experienced levels), by 


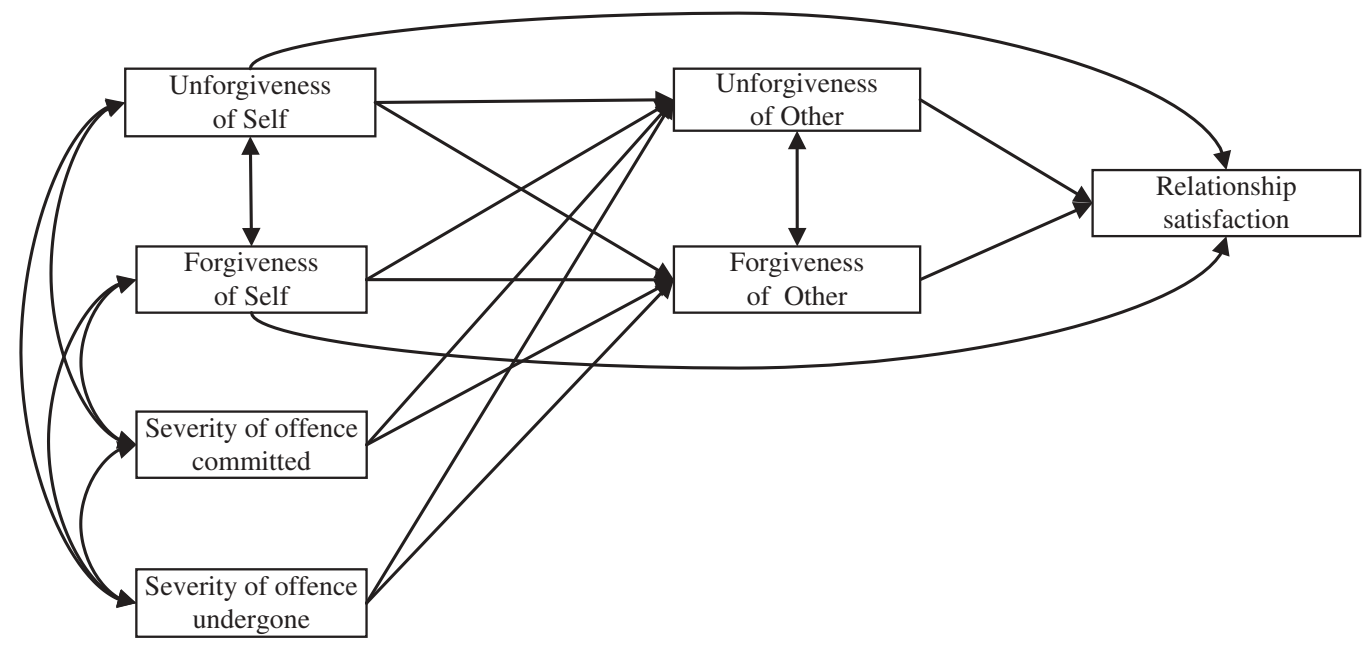

Figure 1. Tested links between the variables of the mediational hypothesized model.

assessing self-forgiveness and other-forgiveness for real transgressions occurring in ongoing couple relationships. Second, unlike Study 1 which was based on dating partners, Study 2 examined the associations between selfforgiveness, other-forgiveness, and relationship satisfaction among stable cohabiting partners.

\section{Method}

\section{Participants and procedure}

One hundred and thirty cohabiting couples took part in the research on a voluntary basis. Couples were recruited by inviting undergraduate students to ask acquaintances who had been married or dating for more than 3 years to participate. Subjects were asked to report a transgression that occurred in the relationship for which they felt responsible. Subjects carried out this assignment in the presence of both their partner and the investigator without much difficulty. After reporting the offence, subjects were invited to briefly describe in writing the offense they perpetrated and to indicate the time since the offence occurred. They were then asked to evaluate their level of self-forgiveness for the transgression committed against the partner as well as their level of other-forgiveness for the offence reported by the partner in which they were the victim.

In order to consider genuine self-forgiveness, only data from subjects who felt at least moderately responsible for the offense committed (scoring 4 or higher on a 7point responsibility item) were analyzed. Also, to test our within subject hypotheses, we selected only those subjects for whom the transgression they reported to have committed against the partner occurred more than three months before the one their partner reported to have inflicted to them. The fact that the offence suffered happened at least 3 months later than the offence perpetrated suggests that other-forgiveness presumably started and occurred later than self-forgiveness. Application of these criteria resulted in a final sample of 92 independent subjects (54 men and 38 women), aged from 26 to 55 years $(M$ age $=36.7 ; S D=8.9), 43 \%$ of whom had a degree. The average length of their relationship was 11 years $(S D=8.4)$.

\section{Measures}

Responsibility. We measured perceived responsibility for the offense committed against the partner with a single item ('To what extent do you feel responsible for the wrongdoing?') rated on a 7-point Likert-type scale $(1=$ not responsible at all; $7=$ responsible at all $)$.

Self-forgiveness. Forgiveness toward the self was assessed using the Self-Forgiveness Scale (Pelucchi et al., 2013). The positive dimension of the scale, named Forgiveness of Self, comprises four items assessing offender benevolence and compassion toward the self, as well as a self-growth process; the negative dimension, called Unforgiveness of Self, comprised seven items assessing the presence of selfresentment and a negative self-view. Items were scored on 7 -point scales, ranging from $1=$ completely disagree to 7 = completely agree. Coefficient alpha was. 71 and .92 for Forgiveness of Self and Unforgiveness of Self dimension, respectively.

Other-forgiveness. As in Study 1, forgiveness toward the partner was assessed using the Marital Offence-specific Forgiveness Scale (MOFS; Paleari et al., 2009) adapted for unmarried partners. Coefficient alpha was .74 and .85 for Forgiveness of Other and Unforgiveness of Other subscale, respectively. 
Relationship satisfaction. Relationship satisfaction was measured with the Quality of Marriage Index (QMI; Norton, 1983). This six-item inventory assesses marital satisfaction with broadly worded, global items (e.g. 'We have a good marriage'). In order to assess relationship satisfaction in unmarried couples, the word 'marriage' in the scale was replaced by the phrase 'couple relationship'. Respondents showed their degree of agreement with each of five items on a 7-point Likert-type scale ranging from 1 (very strong disagreement) to 7 (very strong agreement) and with one item on a 10-point Likert-type scale ranging from 1 (very strong disagreement) to 10 (very strong agreement). Because the data were negatively skewed, the following transformation, recommended by Norton (1983), was used: QMI* $=.001(\Sigma z i+v) 3$, where QMI* is the transformed QMI, $z i$ is the standardized score, and $v$ is the variance across intervals obtained by stratifying the distribution of the QMI into 5\% intervals. Coefficient alpha was .94 .

Severity of offence committed. Similar to Study 1, perceived severity of the transgression perpetrated was assessed with the item 'How serious was the wrongdoing you perpetrated?' rated on a 7-point Likert-type scale $(1=$ not serious at all $; 7=$ very serious $)$.

Severity of the offence experienced. Perceived severity of the transgression suffered was assessed with the item 'How serious was the wrongdoing your partner perpetrated?' rated on a 7-point Liker-type scale $(1=$ not serious at all; $7=$ very serious).

\section{Results}

Correlations among the variables investigated, as shown in Table 2, indicate that most were associated with each other in the expected manner. Unforgiveness and Forgiveness of Self were positively correlated to Unforgiveness and
Forgiveness of Other, respectively. Unforgiveness of Self and Unforgiveness of Other were negatively associated with relationship satisfaction, whereas Forgiveness of Other was positively related to it. Finally, severity of offence committed was positively correlated to both Unforgiveness and Forgiveness of Self and severity of offence undergone was positively associated with Unforgiveness of Other.

We tested the hypothesized mediational model using EQS 6 (Bentler, 2006). The Sobel method (1987) was used to test the statistical significance of indirect (or mediational) effects. Manifest rather than latent variables were entered in the model owing to our sample size. ${ }^{1}$ The model provided an excellent fit to the data $\left(\chi^{2}(2)=.31\right.$, $p=.85, \mathrm{CFI}=1.00$, RMSEA $=.000, \mathrm{AIC}=-3.69)$ and accounted for a substantial amount of variance in relationship satisfaction $\left(R^{2}=.26\right)$. Also, the model fit the data slightly better than an alternative model in which relationship satisfaction predicted other-forgiveness through the mediation of self-forgiveness, while controlling for the severity of the offences committed and suffered $\left(\chi^{2}\right.$ (3) $=3.99, p=.26$, CFI $=0.98$, RMSEA $=.06$, $\mathrm{AIC}=-2.00)$.

The parameter estimates for the hypothesized model, as shown in Figure 2, indicate that, after controlling for both the severity of the offence committed and the severity of the offence suffered, Unforgiveness of the Other and Forgiveness of the Other were significantly related to relationship satisfaction ( $\beta=-.28$ and .24 , respectively). Consistent with our hypotheses, Unforgiveness of Self significantly predicted relationship satisfaction, both directly $(\beta=-.18)$ and indirectly through the mediation of Unforgiveness of Other $(\beta=-.07, p=.06)$ and Forgiveness of Other $(\beta=-.05, p=.02$; overall mediation effect: $\beta=-.12, p=.02$ ). Specifically, independently of the severity of the offences committed and suffered, the more subjects had negative thoughts and feelings toward themselves as a result of their transgression, the

Table 2. Correlations among and descriptive statistics for Study 2 variables.

\begin{tabular}{|c|c|c|c|c|c|c|c|}
\hline & $\begin{array}{l}\text { Unforg. of } \\
\text { Self }\end{array}$ & $\begin{array}{l}\text { Forg. of } \\
\text { Other }\end{array}$ & $\begin{array}{l}\text { Unforg. of } \\
\text { Other }\end{array}$ & $\begin{array}{l}\text { Forg. of } \\
\text { Other }\end{array}$ & $\begin{array}{l}\text { Relat. } \\
\text { Sat. }\end{array}$ & $\begin{array}{l}\text { Sev. Off. } \\
\text { Com. }\end{array}$ & $\begin{array}{l}\text { Sev. Off. } \\
\text { Und. }\end{array}$ \\
\hline 1. Unforgiveness of Self & - & .16 & $.24^{*}$ & -.15 & $-.28 * *$ & $.31 * *$ & .05 \\
\hline 2. Forgiveness of Self & & - & .01 & $.25 *$ & .05 & $.41 * * *$ & -.11 \\
\hline 3. Unforgiveness of Other & & & - & $-.38 * * *$ & $-.41 * * *$ & -.01 & $.27 * *$ \\
\hline 4. Forgiveness of Other & & & & - & $.38 * * *$ & .05 & -.14 \\
\hline 5. Relationship satisfaction & & & & & - & -.06 & -.09 \\
\hline $\begin{array}{l}\text { 6. Severity of offence } \\
\text { committed }\end{array}$ & & & & & & - & .18 \\
\hline $\begin{array}{l}\text { 7. Severity of offence } \\
\text { undergone }\end{array}$ & & & & & & & - \\
\hline$M$ & 2.36 & 4.57 & 2.56 & 4.76 & 34.41 & 4.58 & 4.20 \\
\hline$S D$ & 1.15 & 1.18 & 1.39 & 1.49 & 14.06 & 1.65 & 1.56 \\
\hline
\end{tabular}

Note: ${ }^{*} p<.05 ;{ }^{* *} p<.01 ; * * * p<.001$. 


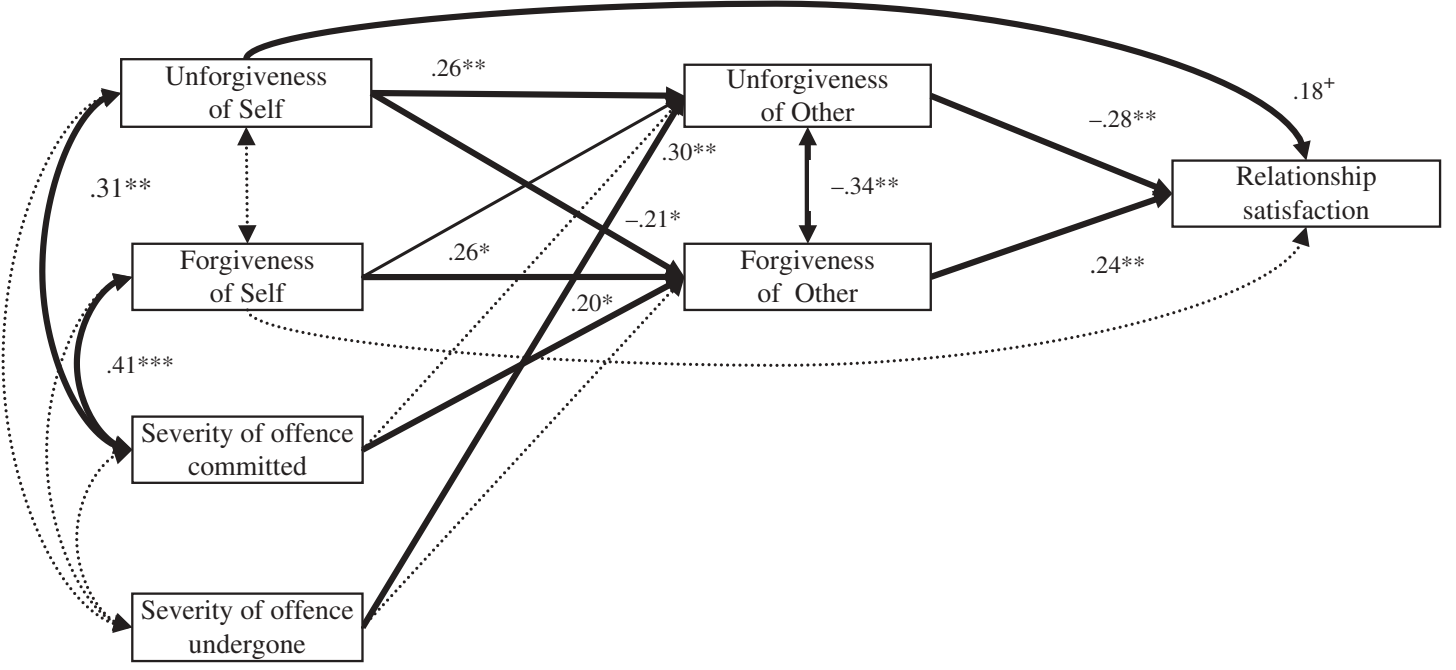

Figure 2. Standardized parameter estimates for the tested mediational model.

Note. ${ }^{+} p<.06 ;{ }^{*} p<.05 ; * * p<.01 ; * * * p<.001$; pointed arrow $=$ no significant path.

less they were satisfied with their romantic relationship. This partly occurred because the more subjects were unforgiving toward the self for offences perpetrated against the partner, the more they were avoidant and revengeful $(\beta=.26)$, and the less they were benevolent $(\beta=-.21)$ toward the partner for offences suffered at his or her hand. Overall, Unforgiveness of Self was related to relationship satisfaction $(\beta=-.30$ for the overall Unforgiveness of Self effect). Even though Forgiveness of Self was significantly related to Forgiveness of Other $(\beta=.26)$, contrary to our hypotheses it did not significantly predict relationship satisfaction, either directly or indirectly $(\beta=.04, \mathrm{~ns})$.

\section{Discussion}

Existing evidence shows that forgiving a partner transgression and forgiving the self for a transgression committed against the partner are both pro-relational processes (e.g. Pelucchi et al., 2013; Strelan \& Covic, 2006). Notwithstanding an increasing number of studies on the topic, the relation between self-forgiveness and other-forgiveness at the intrapersonal level (within subjects) has received little attention. To address this limitation, we examined the association between forgiving the self for a transgression against the partner and forgiving the partner for a transgression against the self (Study 1). We also explored whether the relationship between self-forgiveness and relationship satisfaction is mediated by otherforgiveness (Study 2). Using different methodological approaches, the two studies showed that forgiving the self for a transgression against the partner fostered forgiveness of a subsequent transgression by the partner, which in turn enhances relationship satisfaction.
Specifically, the first study showed that in hypothetical situations, subjects were more likely to forgive the partner as long as they had previously forgiven themselves. Relying on existing studies on forgiveness, self-compassion and human fallibility awareness (Breen, Kashdan, Lenser, \& Fincham, 2010; Exline et al., 2008; Neff, 2003; Wohl et al., 2006), we went on to speculate that self-forgiving people might be more prone to recognize and take into account the fallibility of all human beings. This, in turn, might cause them to be more empathic and forgiving toward their transgressors and is particularly likely to happen in close relationships, like the romantic ones investigated, where each partner's self-image is closely tied to the partner (Aron et al., 1991).

The second study provided evidence that other-forgiveness is a partial mediator of the association between self-forgiveness and relationship satisfaction, when both self-forgiveness and other-forgiveness are evaluated within subjects for real offences that partners reported to have committed and suffered within their relationship. In line with prior research on forgiveness in relationships (e.g. Fincham et al., 2006), the more subjects were benevolent and refrained from being avoidant and revengeful toward their romantic partner, the more they were satisfied with their romantic relationship. Moreover, consistent with our hypothesis, we found that unforgiveness of self was negatively associated with relationship satisfaction partly via unforgiveness of other. That is, the more subjects reduced negative thoughts and feelings towards the self for an offence perpetrated against the partner, the less they were avoidant and vengeful toward the partner for an offence he or she later committed against them, which in turn lead them to be more satisfied with their relationship. Contrary to our hypothesis, we did not find support for an 
analogous mediational path linking forgiveness of self (i.e. the positive dimension of self-forgiveness) to relationship satisfaction via other-forgiveness. As documented in previous research (Paleari et al., 2009; Pelucchi et al., 2013), the negative dimension of both self-forgiveness and otherforgiveness tends to have a greater impact on relationship satisfaction than the positive dimension. This could be because from an evolutionary perspective, being able to recognize and control negative emotions and/or situations is more adaptive than being able to recognize and control positive ones (e.g. Rozin \& Royzman, 2001).

\section{Limitations and conclusion}

The findings of the present studies need to be viewed in the context of several limitations. First, owing to the small sample size, we could not examine whether our results were moderated by gender. Existing research on interpersonal forgiveness in couples shows that women are more pro-social but less forgiving than men, whereas men's unforgiveness has stronger effects on relationship quality, both within and across partners (cf. Paleari et al., $2005,2010)$. On the other hand, studies on self-forgiveness for transgressions occurring within couples showed no differences between men and woman in forgiving the self (Pelucchi et al., 2013; Thompson et al., 2005). Thus, further studies are needed to understand whether the associations between self-forgiveness, other-forgiveness, and relationship satisfaction vary across gender.

Second, although the results obtained in Study 1 support the predicted effect of self-forgiveness on other-forgiveness, Study 2 results should be interpreted cautiously because of their cross-sectional nature. Longitudinal research is needed to better explore direction of effects among self- and other-forgiveness and relationship satisfaction.

Finally, we do not know whether the present findings are specific to the close relationship context or whether they occur in other types of relationships. Future research might examine whether the associations found vary its strength as a function of the degree of closeness between the offender and the victim.

Notwithstanding these limitations, the findings of the present studies have interesting implications for future research on self-forgiveness as well as intervention research for improving couple well-being. Researchers have shown that happily married spouses in long-standing marriages rate interpersonal forgiveness as one of the top ten factors that helped them sustain a long-term marriage (Fenell, 1993). Similarly, therapists have developed numerous couple interventions to increase partners' interpersonal forgiveness abilities (e.g. Gordon, Baucom, \& Synder, 2000; McCullough, 1997; Worthington, 1998; for a review, see Wade, Hoyt, Kidwell, \& Worthington, 2014). By showing that partners' other-forgiveness can be fostered by self-forgiveness, the present research suggests that intervention programs promoting self-forgiveness abilities might have important implications not only for personal health, but also for the well-being of intimate relationships. Whether such self-forgiveness programs are efficacious by themselves or are best used as adjuncts to other interventions remains to be determined.

\section{Disclosure statement}

No potential conflict of interest was reported by the authors.

\section{Note}

1. Even though the ratio of subjects to estimated parameters was 3.5 in the model tested, that is lower than the 5 one recommended by some others (e.g. Bentler \& Chou, 1987), some subsequent works (McCallum, Browne, \& Sugawara, 1996) on the question of sample size in SEM has shown that it is impossible to derive a minimum ratio that is appropriate in all situations, rather the minimum sample size is highly dependent on several characteristics, including the average communality of measured variables. When communalities are high ( $>.6)$, as they are in the present study, sample sizes of about 100 subjects are often adequate.

\section{References}

Allemand, M., Amberg, I., Zimprich, D., \& Fincham, F. D. (2007). The role of trait forgiveness and relationship satisfaction in episodic forgiveness. Journal of Social and Clinical Psychology, 26, 199-217. doi:10.1521/ jscp.2007.26.2.199

Aron, A., Aron, E. N., Tudor, M., \& Nelson, G. (1991). Close relationships as including other in the self. Journal of Personality and Social Psychology, 60, 241-253. doi:10.1037/0022-3514.60.2.241

Baker, L. R., McNulty, J. K., Overall, N. C., Lambert, N. M., \& Fincham, F. D. (2013). How do relationship maintenance behaviors affect individual well-being? A contextual perspective. Social Psychological and Personality Science, 4, 282-289. doi:10.1177/1948550612452891

Baumeister, R. F., Bratslavsky, E., Finkenauer, C., \& Vohs, K. D. (2001). Bad is stronger than good. Review of General Psychology, 5, 323-370. doi:10.1037/1089-2680.5.4.323

Bentler, P. M. (2006). EQS (Version 6.1) [Computer software]. Encino, CA: Multivariate Software.

Bentler, P. M., \& Chou, C.-P. (1987). Practical issues in structural modeling. Sociological Methods \& Research, 16, 78117. doi:10.1177/0049124187016001004

Bookwala, J. (2012). Marriage and other partnered relationships in middle and late adulthood. In R. Blieszner \& V. H. Bedford (Eds.), Handbook of aging and the family (2nd ed., pp. 91-124). Santa Barbara, CA: ABC-CLIO.

Breen, W. E., Kashdan, T. B., Lenser, M. L., \& Fincham, F. D. (2010). Gratitude and forgiveness: Convergence and divergence on self-report and informant ratings. Personality and Individual Differences, 49, 932-937. doi:10.1016/j. paid.2010.07.033

Carr, D., Freedman, V. A., Cornman, J. C., \& Schwarz, N. (2014). Happy marriage, happy life? Marital quality and 
subjective well-being in later life. Journal of Marriage and Family, 76, 930-948. doi:10.1111/jomf.12133

Davila, J., Karney, B. R., Hall, T. W., \& Bradbury, T. N. (2003). Depressive symptoms and marital satisfaction: Within-subject associations and the moderating effects of gender and neuroticism. Journal of Family Psychology, 17, 557-570. doi:10.1037/0893-3200.17.4.557

Dillon, R. S. (2001). Self-forgiveness and self-respect. Ethics, 112, 53-83. doi:10.1086/339140

Eaton, J., Struthers, C. W., \& Santelli, A. G. (2006). Dispositional and state forgiveness: The role of selfesteem, need for structure, and narcissism. Personality and Individual Differences, 41, 371-380. doi:10.1016/j. paid.2006.02.005

Enright, R. D., \& The Human Development Study Group. (1996). Counseling within the forgiveness triad: On forgiving, receiving forgiveness, and self-forgiveness. Counseling and Values, 40, 107-126. doi:10.1002/j.2161-007X.1996. tb00844.x

Exline, J. J., Baumeister, R. F., Zell, A. L., Kraft, A. J., \& Witvliet, C. V. (2008). Not so innocent: Does seeing one's own capability for wrongdoing predict forgiveness? Journal of Personality and Social Psychology, 94, 495-515. doi:10.1037/0022-3514.94.3.495

Fenell, D. (1993). Characteristics of long-term first marriages. Journal of Mental Health Counseling, 15, 446-460.

Fincham, F. D., \& Beach, S. R. H. (2007). Forgiveness and marital quality: Precursor or consequence in well-established relationships? The Journal of Positive Psychology, 2, 260 268. doi:10.1080/17439760701552360

Fincham, F. D., Hall, J., \& Beach, S. R. H. (2006). Forgiveness in marriage: Current status and future directions. Family Relations, 55, 415-427. doi:10.1111/j.1741-3729.2005.callf.x-i1

Fincham, F. D., Jackson, H., \& Beach, S. R. H. (2005). Transgression severity and forgiveness: Different moderators for objective and subjective severity. Journal of Social and Clinical Psychology, 24, 860-875. doi:10.1521/ jscp.2005.24.6.860

Fisher, M. L., \& Exline, J. J. (2006). Self-forgiveness versus excusing: The roles of remorse, effort, and acceptance of responsibility. Self and Identity, 5, 127-146. doi:10.1080/ 15298860600586123

Gordon, K. C., Baucom, D. H., \& Snyder, D. K. (2000). The use of forgiveness in marital therapy. In M. E. McCullough, K. I. Pargament, \& C. E. Thoresen (Eds.), Forgiveness: Theory, research, and practice (pp. 203-227). New York, NY: Guilford Press.

Gordon, K. C., Hughes, F. M., Tomcik, N. D., Dixon, L. J., \& Litzinger, S. (2009). Widening spheres of impact: The role of forgiveness in marital and family functioning. Journal of Family Psychology, 23, 1-13. doi:10.1037/a0014354

Hall, J. H., \& Fincham, F. D. (2005). Self-forgiveness: The stepchild of forgiveness research. Journal of Social \& Clinical Psychology, 24, 621-637. doi:10.1521/jscp.2005.24.5.621

Hall, J. H., \& Fincham, F. D. (2008). The temporal course of self-forgiveness. Journal of Social and Clinical Psychology, 27, 174-202. doi:10.1521/jscp.2008.27.2.174

Hodgson, L. K., \& Wertheim, E. H. (2007). Does good emotion management aid forgiving? Multiple dimensions of empathy, emotion management and forgiveness of self and others. Journal of Social and Personal Relationships, 24, 931949. doi:10.1177/0265407507084191

Holmgren, M. R. (1998). Self-forgiveness and responsible moral agency. The Journal of Value Inquiry, 32, 75-91. doi:10.1023/A:1004260824156
Karremans, J. C., Van Lange, P. A. M., Ouwerkerk, J. W., \& Kluwer, E. S. (2003). When forgiving enhances psychological well-being: The role of interpersonal commitment. Journal of Personality and Social Psychology, 84, 10111026. doi:10.1037/0022-3514.84.5.1011

Macaskill, A., Maltby, J., \& Day, L. (2002). Forgiveness of self and others and emotional empathy. The Journal of Social Psychology, 142, 663-665. doi:10.1080/00224540209603925

MacCallum, R. C., Browne, M. W., \& Sugawara, H. M. (1996). Power analysis and determination of sample size for covariance structure modeling. Psychological Methods, 1, 130 149. doi:10.1037/1082-989X.1.2.130

MacKenzie, J., Smith, T. W., Uchino, B., White, P. H., Light, K. C., \& Grewen, K. M. (2014). Depressive symptoms, anger/ hostility, and relationship quality in young couples. Journal of Social and Clinical Psychology, 33, 380-396. doi:10.1521/jscp.2014.33.4.380

Maltby, J., Macaskill, A., \& Day, L. (2001). Failure to forgive self and others: A replication and extension of the relationship between forgiveness, personality, social desirability, and general health. Personality and Individual Differences, 30, 881-885. doi:10.1016/S0191-8869(00)00080-5

Mauger, P. A., Perry, J. E., Freeman, T., Grove, D. C., McBride, A. G., \& McKinney, K. (1992). The measurement of forgiveness: Preliminary research. Journal of Psychology and Christianity, 11, 170-180.

McCullough, M. E. (1997). Marriage and forgiveness. Marriage and Family: A Christian Journal, 1, 81-96.

McCullough, M. E., Rachal, K. C., Sandage, S. J., Worthington, Jr., E. L, Brown, S. W., \& Hight, T. L. (1998). Interpersonal forgiving in close relationships: II. Theoretical elaboration and measurement. Journal of Personality and Social Psychology, 75, 1586-1603. doi:10.1037/0022-3514.75.6.1586

McCullough, M. E., Worthington, Jr., E. L., \& Rachal, K. C. (1997). Interpersonal forgiving in close relationships. Journal of Personality and Social Psychology, 73, 321336. doi:10.1037/0022-3514.73.2.321

Neff, K. D. (2003). Self-compassion: An alternative conceptualization of a healthy attitude toward oneself. Self and Identity, 2, 85-101. doi:10.1080/15298860309032

Norton, R. (1983). Measuring marital quality: A critical look at the dependent variable. Journal of Marriage and the Family, 45, 141-151. doi:10.2307/351302

Paleari, F. G., Regalia, C., \& Fincham, F. D. (2005). Marital quality, forgiveness, empathy, and rumination: A longitudinal analysis. Personality and Social Psychology Bulletin, 31, 368-378. doi:10.1177/0146167204271597

Paleari, F. G., Regalia, C., \& Fincham, F. D. (2009). Measuring offence-specific forgiveness in marriage: The Marital Offence-specific Forgiveness Scale (MOFS). Psychological Assessment, 21, 194-209. doi:10.1037/a0016068

Paleari, F. G., Regalia, C., \& Fincham, F. D. (2010). Forgiveness and conflict resolution in close relationships: Within and cross partner effects. Universitas Psychologica, 9, 35-56.

Pelucchi, S., Paleari, F. G., Regalia, C., \& Fincham, F. D. (2013). Self-forgiveness in romantic relationships: It matters to both of us. Journal of Family Psychology, 27, 541-549. doi:10.1037/a0032897

Rozin, P., \& Royzman, E. B. (2001). Negativity bias, negativity dominance, and contagion. Personality and Social Psychology Review, 5, 296-320. doi:10.1207/ S15327957PSPR0504 2

Schmitt, M., Gollwitzer, M., Förster, N., \& Montada, L. (2004). Effects of objective and subjective account components on 
forgiving. The Journal of Social Psychology, 144, 465-486. doi:10.3200/SOCP.144.5.465-486

Snow, N. E. (1993). Self-forgiveness. The Journal of Value Inquiry, 27, 75-80. doi:10.1007/BF01082713

Sobel, M. E. (1987). Direct and indirect effects in linear structural equation models. Sociological Methods \& Research, 16, 155-176. doi:10.1177/0049124187016001006

Strelan, P., \& Covic, T. (2006). A review of forgiveness process models and a coping framework to guide future research. Journal of Social \& Clinical Psychology, 25, 1059-1085. doi:10.1521/jscp.2006.25.10.1059

Tangney, J. P., Boone, A. L., \& Dearing, R. (2005). Forgiving the self: Conceptual issues and empirical findings. In E. L. Worthington, Jr. (Ed.), Handbook of forgiveness (pp. 143158). New York, NY: Brunner-Routledge.

Tangney, J. P., Boone, A. L., Dearing, R. L., \& Reinsmith, C. (2002). Individual differences in the propensity to forgive: Measurement and implications for psychological and social adjustment. Paper presented at the 1999 American Psychological Association Convention, Boston, MA.

Thompson, L. Y., Snyder, C. R., Hoffman, L., Michael, S. T., Rasmussen, H. N., Billings, L. S., ... Roberts, D. E. (2005). Dispositional forgiveness of self, others, and situations. Journal of Personality, 73, 313-360. doi:10.1111/j.14676494.2005.00311.x

Tsang, J., McCullough, M. E., \& Fincham, F. D. (2006). The longitudinal association between forgiveness and relationship closeness and commitment. Journal of Social and Clinical Psychology, 25, 448-472. doi:10.1521/ jscp.2006.25.4.448

Wade, N. G., Hoyt, W. T., Kidwell, J. E. M., \& Worthington, E. L. (2014). Efficacy of psychotherapeutic interventions to promote forgiveness: A meta-analysis. Journal of
Consulting and Clinical Psychology, 82, 154-170. doi:10.1037/a0035268

Wenzel, M., Woodyatt, L., \& Hedrick, K. (2012). No genuine self-forgiveness without accepting responsibility: Value reaffirmation as a key to maintaining positive self-regard. European Journal of Social Psychology, 42, 617-627. doi:10.1002/ejsp.1873

Whisman, M. A., \& Bruce, M. L. (1999). Marital dissatisfaction and incidence of major depressive episode in a community sample. Journal of Abnormal Psychology, 108, 674-678. doi:10.1037/0021-843X.108.4.674

Wieselquist, J., Rusbult, C. E., Foster, C. A., \& Agnew, C. R. (1999). Commitment, pro-relationship behavior, and trust in close relationships. Journal of Personality and Social Psychology, 77, 942-966. doi:10.1037/0022-3514.77.5.942

Wohl, M. J. A., DeShea, L., \& Wahkinney, R. L. (2008). Looking within: Measuring state self-forgiveness and its relationship to psychological well-being. Canadian Journal of Behavioural Science/Revue Canadienne Des Sciences Du Comportement, 40, 1-10. doi:10.1037/0008400x.40.1.1.1

Wohl, M. J. A., Kuiken, D., \& Noels, K. A. (2006). Three ways to forgive: A numerically aided phenomenological study. British Journal of Social Psychology, 45, 547-561. doi:10.1348/014466605X53695

Woodyatt, L., \& Wenzel, M. (2013). Self-forgiveness and restoration of an offender following an interpersonal transgression. Journal of Social and Clinical Psychology, 32, 225-259. doi:10.1521/jscp.2013.32.2.225

Worthington, Jr., E. L. (1998). An empathy-humility-commitment model of forgiveness applied within family dyads. Journal of Family Therapy, 20, 59-76. doi:10.1111/14676427.00068 